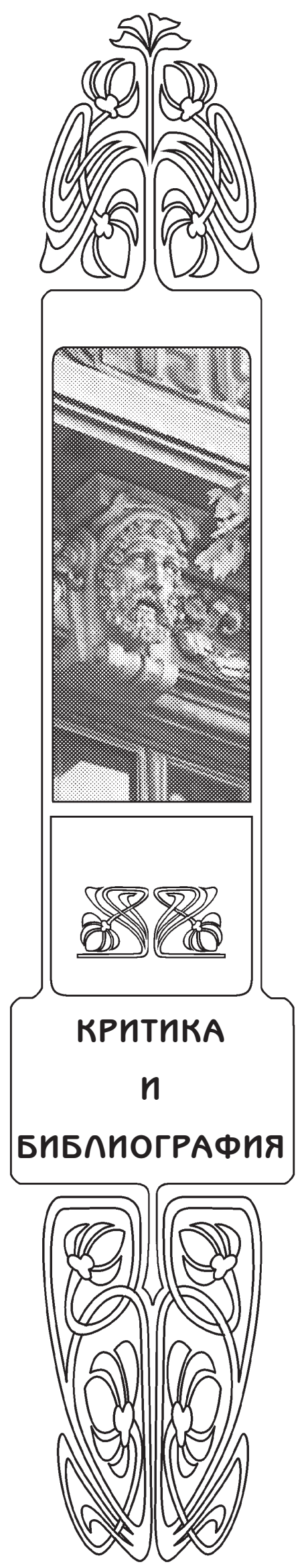

\title{
ПРЕДСТАВЛЯЕМ КНИГУ
}

УДК 811.161.1'38:070+929Клушина

\section{Книга, которую филологам стоит прочитать}

(Клушина Н. И. Медиастилистика. М. : Флинта, 2018. 184 с.)

\section{О. Б. Сиротинина}

Сиротинина Ольга Борисовна, доктор филологических наук, профессор кафедры русского языка, речевой коммуникации и русского как иностранного, Саратовский национальный исследовательский государственный университет имени Н. Г. Чернышевского, skunak@mail.ru

Статья является рецензией на книгу Н. И. Клушиной «Медиастилистика», в которой рассмотрены положения, меняющие привычные для филологов представления о современной и советской культуре, литературном русском языке и отраслях науки о нем и о речи в СМИ.

Ключевые слова: стилистика, медиастилистика, медиалингвистика, варианты литературного языка, стиль, медийный язык.

\section{A Book that Philologists Should Read}

(Klushina N. I. Media Stylistics. Moscow, Flinta, 2018. 184 p.)

\section{B. Sirotinina}

Olga B. Sirotinina, http://orcid.org/0000-0002-3258-4536, Saratov State University, 83 Astrakhanskaya St., Saratov 410012, Russia, skunak@mail.ru

This article is a review of the book by N. I. Klushina Media Stylistics, which considers aspects that change conventional philological views on modern and soviet culture, the literary Russian language, fields of science that study it, and speech in mass media.

Keywords: stylistics, media stylistics, media linguistics, variants of literary language, style, media language

DOI: https://doi.org/10.18500/1817-7115-2019-19-4-488-489

В 2018 г. в серии «Научные дискуссии» издательства «Флинта» вышла монография Наталии Ивановны Клушиной (доктора филологических наук, профессора факультета журналистики МГУ им. М. В. Ломоносова и председателя стилистической комиссии Международного комитета славистов) «Медиастилистика» (М.: Флинта, 2018. 184 с.).

Монография Н. И. Клушиной действительно дискуссионная, но, безусловно, заслуживает внимания не только стилистов и лингвистов вообще, но и тех, кто имеет дело с журналистикой, тем более готовит журналистов, и вообще всех, кто интересуется проблемами и судьбой современного русского языка.

Одно из выдвигаемых Н. И. Клушиной положений - доказывание, что современный русский литературный язык имеет два варианта: национальный эталонный, на который ориентируется интеллектуальная элита общества с элитарной речевой культурой, и медийный язык, которым пользуются массовые СМИ (качественные ориентируются на эталонный) и таблоидные, а также социальные сети Интернета, который Н. И. Клушина причисляет к СМИ, и основные массы населения России, влияющие своей практикой общения на изменения в медийном языке.

Медийный вариант (в терминологии Н. И. Клушиной медиастиль) литературного языка менее традиционен, более эмоционален и податлив на эксперименты. Конечно, такое мнение дискуссионно, но 
имеет основания и заслуживает внимания. Аналогично обстоит дело с пониманием и употреблением в монографии терминов стиль, дискурс, медиадискурс.

Вряд ли можно оспорить утверждение Н. И. Клушиной, что современные СМИ превратились в продавцов новостей, отказавшись от своей просветительской миссии и создавая видимость свободы разных мнений путем разноголосья. Но явно дискуссионны суждения о том, что конкуренция создается только разными социальными и особенно эмоциональными «обертками» новостей, а ценность самой информации при этом снижается.

Заслуживает внимания выделение прямого и косвенного адресата СМИ. Несомненно, стоит прислушаться к заявленному Н. И. Клушиной повышению роли стилистики как науки, создающей творческое использование языка на основе выбора наиболее эффективных средств для выражения авторских интенций, а также стоит внимательно рассмотреть включенный в текст монографии терминологический словарь. Однако, с моей точки зрения, было бы целесообразней разместить его не в конце, а в начале текста, это облегчило бы его восприятие. Своим студентам я буду рекомендовать начать чтение монографии Н. И. Клушиной с него. Некоторые термины вообще вводятся Н. И. Клушиной впервые, другие уточняют, а иногда и меняют свое употребление (например термин дискурс, используемый Н. И. Клушиной только в значении «совокупность текстов какой-либо тематики», а не «речь, опрокинутая в жизнь»).

Не все, что предлагает Н. И. Клушина, надо принимать, со многим можно и нужно спорить, но знать ее мнение, учитывать его, иногда коренным образом меняющее прежние взгляды на роль СМИ, стилистику, медиастиль, отличающийся от публицистического, заимствования из других языков и т. д. при рассмотрении фактов языка и речи. Это не просто «игра» в новые термины, а результат серьезных размышлений над фактами.

Полезно и студентам, и всем читателям книги ознакомление с взглядами Н. И. Клушиной по отношению к советским СМИ, с размещенными в заключении суждениями известного польского ученого Станислава Гайды и предложениями авторитетного австрийского ученого Б. Тошовича. Уверена, что любой филолог (и не только филолог) найдет в монографии очень много нужного ему, заставит над многим задуматься.

\section{Образец для цитирования:}

Сиротинина О. Б. Книга, которую филологам стоит прочитать // Изв. Сарат. ун-та. Нов. сер. Сер. Филология. Журналистика. 2019. Т. 19, вып. 4. С. 488-489. DOI: https://doi.org/10.18500/1817-7115-2019-19-4-488-489

Cite this article as:

Sirotinina O. B. A Book that Philologists Should Read. Izv. Saratov Univ. (N. S.), Ser. Philology. Journalism, 2019, vol. 19, iss. 4, pp. 488-489 (in Russian). DOI: https://doi.org/10.18500/1817-7115-2019-19-4-488-489 